\title{
Screening of endophytic fungi from oil palm (Elaeis guineensis) in producing exopolysaccharides
}

\author{
YURNALIZA YURNALIZA ${ }^{\natural}$, IT JAMILAH, ADRIAN HARTANTO, ANISA LUTFIA \\ Department of Biology, Faculty of Mathematics and Natural Sciences, Universitas Sumatera Utara, Jl. Bioteknologi No. 1, Medan 20155, North Sumatra, \\ Indonesia. Tel./fax.: +62-61- 8214290, `email: yurnaliza@usu.ac.id
}

Manuscript received: 1 February 2021. Revision accepted: 24 February 2021

\begin{abstract}
Yurnaliza Y, Jamilah I, Hartanto A, Lutfia A. 2021. Screening of endophytic fungi from oil palm (Elaeis guineensis) in producing exopolysaccharides. Biodiversitas 22: 1467-1473. Exopolysaccharides (EPS) are microbial polysaccharides with a high biotechnological application in many fields due to their bioactivity and biocompatibility. Endophytic fungi are potential agents for producing EPS even though they remained under-exploited, especially those originating as indigenous strains from oil palm (Elaeis guineensis Jacq.). The present study reports on EPS production by a collection of endophytic fungi isolated from the petioles of oil palm under submerged fermentation. The culture medium was formulated with sucrose as C-source to trigger the secretion of EPS by the strains. Isolation of EPS was done through absolute ethanol precipitation in cold conditions. A total of 29 endophytic fungal strains was recovered from the foliar part of the plants. Molecular identification based on ITS-rDNA region and phylogenetic construction of each lineage revealed the dominant species from Pestalotiopsidaceae (syn. Amphisphaeriaceae), followed by Hypoxylaceae, Pleosporaceae, Didymosphaeriaceae, Sporocadaceae, and other minor families. In general, most isolates were ascomycetous fungi along with a basidiomycetous and zygomycetous fungus. After fermentation for 10 days, three fungal endophytes identified as Annulohypoxylon thailandicum P8 (Hypoxylaceae), Pseudopestalotiopsis simitheae P1 (Pestalotiopsidaceae), and Diaporthe eucalyptorum P11 (Diaporthaceae) secreted EPS higher in values than the others. The most prominent strain was $A$. thailandicum P8 with a yield of $>50$ $\mathrm{mg} / 100 \mathrm{~mL}$ of filtrate solution. Based on FT-IR spectral analysis, the EPS product was detected to contain carboxyl, carbonyl, glycosidic bonds, and hydroxyl groups hereafter confirmed the characteristics of exopolysaccharides. The results demonstrated that the EPS may be evaluated for its bioactivity in a future study.
\end{abstract}

Keywords: Ascomycetes, endophytes, exopolysaccharides, oil palm, Pestalotiopsis

\section{INTRODUCTION}

Exopolysaccharides (EPS) is an example of important polysaccharides derived from microbial sources with many potential application in industrial and development scales (Donot et al. 2012; Nwodo et al. 2012). These biopolymers are metabolic products accumulated on the microbial cell surface, contains more than 20 monosaccharide units linked by glycosidic bonds which provide the structural stabilization and protection needed to cope with harsh and stressful environment (Mahapatra and Banerjee 2012). Due to its versatility in terms of physiological, rheological, and biological properties, microbial EPS has been isolated thoroughly, purified, and integrated into a wide range of applications such as chemicals, cosmeceuticals, foods, packaging materials, and pharmaceuticals (Ates 2015; Ruffing and Chen 2006). Microbial EPS is more preferred than plant- or animal-derived polysaccharides mainly due to its reproducibility, ease of product recovery, and mass production under simple culture conditions with high yield of the final products (Moscovici 2015). There has been an increasing effort in exploring potential and novel microbial species, particularly bacterial and fungal species, which are capable of producing these macromolecules for further strain identification and improvement (Liu et al. 2016). Although EPS-producing microorganisms have been isolated from different natural sources ranging from aquatic to terrestrial environments, even the extreme environments yet some niches are still under-studied. This may provide clue on the vast diversity of both microbial sources and their EPS components (Maugeri et al. 2002; Mata et al. 2006; Satpute et al. 2010; Kavita et al. 2011).

Endophytic fungi are a group of microorganisms colonizing the internal tissue of a plant without causing any apparent harm to their host for at least some parts of their life cycle (Kusari et al. 2014). The extent of this relationship between a host plant and its associated fungi may be seen as a mutualistic symbiosis over the course of their lives (Tan and Zou 2001). Endophytic fungi have been considered as prominent bioresources of novel biomolecules and biologically active compounds in recent decades. Their capacity in producing secondary metabolites through fermentation with agricultural, biotechnological, industrial, and pharmaceutical prospects for downstream production and bio-economic development (Newman and Cragg 2015; Nisa et al. 2015; Manganyi and Ateba 2020; Torres-Mendoza et al. 2020). The first step in studying these fungi is through the isolation and identification of potential fungal strains which may be distinct for each host due to differentials in host species, sampling strategy and culture conditions (Zhang et al. 2017). In the past ten years, several researchers have revealed that endophytic fungi are also regarded as prolific producers of bioactive EPS from diverse hosts and environments (Chen et al. 2011; Dong et 
al. 2014; Mahapatra and Banerjee 2016; Zhang et al. 2017). The potential in finding novel EPS-producing fungal strains is still highly possible especially those originating from tropical plant species including those from Indonesia.

Oil palm (Elaeis guineensis Jacq.) is an important plantation crop species in North Sumatera with high economic benefit in the form of export of quality palm oil. The palm species have been documented to be highly colonized by several species of fungal endophytes (Pinruan et al. 2010; Yurnaliza et al. 2014; Yurnaliza et al. 2017). In a preliminary study, we reported the occurrence of endophytic fungi isolated from the midrib of oil palm leaves that produced EPS under fermentation conditions (Yurnaliza and Jamilah 2018). In this current study, a large population of fungal endophytes (29 strains) was further isolated and identified from the foliar parts or petioles of oil palm.

\section{MATERIALS AND METHODS}

\section{Sampling site}

Elaeis guineensis trees were collected from three oil palm plantations at Medan City, North Sumatra, Indonesia as previously described in our study (Yurnaliza et al. 2020). Foliar parts of each oil palm tree were sampled adequately and randomly cut after removing the spines from the petioles. The petioles were stored in cool box and processed immediately in the laboratory for fungal isolation.

\section{Isolation and identification of endophytic fungi}

The petioles were cut into $30-\mathrm{cm}$ pieces before processing and cleaned with running tap water for $20 \mathrm{~min}$. The procedure in surface sterilizing the foliar part was modified from previous studies on palm endophytes (Pinruan et al. 2010; Yurnaliza et al. 2014). The petioles were cut into $1-2 \mathrm{~cm}$ pieces $(2 \times 2 \mathrm{~cm})$ and sterilized with 95\% (v/v) ethanol for $1 \mathrm{~min}, 3 \%(\mathrm{v} / \mathrm{v})$ sodium hypochlorite for $10 \mathrm{~min}$, and $95 \%(\mathrm{v} / \mathrm{v})$ ethanol for $30 \mathrm{secs}$. All segments were rinsed with sterile distilled water and dried on sterile filter paper. Each segment was placed on top of Potato Dextrose Agar (PDA) medium supplemented with $0.1 \mathrm{mg} \cdot \mathrm{mL}^{-1}$ chloramphenicol to inhibit the bacterial growth. Plates were incubated at ambient temperature for 7 days. Each day, a newly growing hypha was sub-cultured and purified into a new medium. A collection of oil palm endophytic fungi was documented and preserved for the next experimentation. Duplicate fungal specimens were transferred to Macrogen, Inc. (Singapore) for DNA extraction, PCR amplification, and DNA sequencing on the basis of ITS-rDNA using universal primer (ITS1-ITS4) for fungal identification.

\section{DNA sequence analysis}

Complete internal transcribed spacer (ITS) region of each fungal strain was given in raw sequences processed manually using MEGA X (Kumar et al. 2018). The identity of each fungal sequence was first searched using BLAST by selecting the optimized database for rRNA/ITS databases from fungi type and reference material to obtain the closest sequences from the GenBank database. The phylogenetic construction of ITS region was used to clarify the generic level of endophytic fungal isolates with BLAST results since some results may not be clear (Koski and Golding 2001). DNA sequences were multiple aligned using MUSCLE featured in the software and adjusted manually (Edgar 2004). The phylogenetic tree was inferred by using the Maximum Likelihood method and Tamura-3 parameter model (Tamura 1992). The ITS-rDNA sequences of each identified strain were submitted to the GenBank database.

\section{Fermentation and production of EPS by oil palm endophytic fungi}

Submerged fermentation for EPS production of each fungal isolate was based on modified culture conditions previously described by Selbmann et al. (2002) by replacing sorbitol with sucrose as the carbon source. The medium composition $(\mathrm{g} / \mathrm{L})$ were $\mathrm{KCl}, 0.5 ; \mathrm{KH}_{2} \mathrm{PO}_{4}, 1.0$; $\mathrm{MgSO}_{4} .7 \mathrm{H}_{2} \mathrm{O}, 0.5 ; \mathrm{NaNO}_{3}, 3.0$; yeast extract, 1.0; sucrose, 30.0 with the adjusted $\mathrm{pH}$ of final medium at 6.0 using $\mathrm{HCl}$ $1 \mathrm{~N}$ solution (Yurnaliza and Jamilah 2018). Ten mycelial plugs $(\varnothing 6 \mathrm{~mm})$ were inoculated into a $500-\mathrm{mL}$ flask containing $100 \mathrm{~mL}$ of medium and incubated on a rotary shaker at $130 \mathrm{rpm}$ at $28^{\circ} \mathrm{C}$ for 10 days. Mycelial mats were filtered on a Whatman filter paper No. 1 then the filtrates were used for EPS precipitation at $4{ }^{\circ} \mathrm{C}$ by adding $2 \times$ volumes of absolute ethanol (1:2) into the filtrates. The precipitated EPS was filtered and centrifuged at $10,000 \times \mathrm{g}$ for $5 \mathrm{~min}$. The resulting supernatant was dried at $90{ }^{\circ} \mathrm{C}$ until constant weight $(\mathrm{mg})$ as the yield of EPS.

\section{FT-IR spectroscopy}

The fungal isolate that produced significant amount of EPS was subjected to product analysis. A total of $2 \mathrm{mg}$ of dried EPS was mixed with $200 \mathrm{mg}$ of potassium bromide $(\mathrm{KBr})$ powder, pulverized and then formed into a $1 \mathrm{~mm}$ pellets for Fourier transform - infrared (FT-IR) analysis with detection at $4000-400 \mathrm{~cm}^{-1}$. FT-IR analysis was performed in IRPrestige-21 Shimadzu ${ }^{\circledR}$ spectrophotometer (Japan).

\section{RESULTS AND DISCUSSION}

A total of 29 endophytic fungal isolates were recovered from the petioles of oil palm planted in Medan City, North Sumatra. Despite the high number of culturable isolates, most isolates showed a similarity in colony color characteristics from white to dull or black upper colonies which grew fast during the 7 days of incubation. Filamentous and irregular colonies constituted the largest colony form in this study. Based on the morphological features, a microscopic examination was conducted to see the presence of asexual spore for genera level identification. The dominant shape of conidia from our isolates was characterized as fusiform, thick-walled, having mostly four to five-septated or 4/5-celled conidia with simple or branched apical appendages (setulae), which 
gave us clues on the unique characteristics of Pestalotiopsis (Figure 1). Accurate identification of fungal isolates was achieved through ITS-rDNA sequencing analysis. Based on BLAST results, the endophytic fungal isolates were mostly members of Ascomycota $(93 \%, 27 / 29)$, followed by a basidiomycetous and a zygomycetous fungus. The number of species per family is presented in Figure 2.

The dominant family of endophytic fungi from oil palm is Pestalotiopsidaceae, followed by Hypoxylaceae, Pleosporaceae, Didymosphaeriaceae, Sporocadaceae, and other minor families following their EPS production (Table 1). The identity percentage of the results was ranged between 90 and $100 \%$ of similarity. In addition, a phylogenetic tree was constructed to depict a precise species identification based on its nucleotide analysis (Figure 3). The optimal tree with the highest likelihood (3074.35) was shown. Based on the construction, it can be seen that Neopestalotiopsis, Pseudopestalotiopsis, and Pestalotiopsis formed a monophyletic clade and found as the dominant species from oil palm. The current finding of Pestalotiopsidaceae (syn. Amphisphaeriaceae) members as dominant fungal endophytes in oil palm is still considered as common since the members of the family may be found in both tropical and temperate ecosystems (Watanabe et al. 2010). Members of Pestalotiopsidaceae have received much attention due to its ability in producing many bioactive secondary metabolites in laboratory tests rather than its pathogenicity (Strobel 2002; Aly et al. 2010). However, a first report in Thailand revealed that a strain of Pestalotiopsis theae caused a leaf spot disease in oil palm which was further confirmed through pathogenicity test and molecular identification (Suwannarach et al. 2013). In a more recent study, the finding of Pestalotiopsis, Neopestalotiopsis, and Pseudopestalotiopsis in oil palm trees cultivated in Brazil revealed that these fungi may cause some lesions to the oil palm leaves although not directly related to serious disease (de Assis Costa et al. 2018).

Pestalotiopsidaceae is an important Ascomycete family belonging to Xylariales that commonly exhibit weak pathogenicity with lifestyle as endophytes (Jeewon et al. 2003). The relationship between the occurrence of Pestalotiopsis and oil palm cultivated in North Sumatra is still unknown, and is worth investigation, especially on the onset of possible unreported diseases. Similar to a previous report in Thailand, a high number of other Xylariaceous taxa (Hypoxylaceae) was also reported in our study from the genera Annulohypoxylon and Hypoxylon (Pinruan et al. 2010). Other minor fungal species identified in this study, i.e. Beltraniella acacieae, Daldinia starbaeckii, Endomelanconiopsis endophytica, Poitrasia circinans, Paracamarosporium fagi, and Pseudopithomyces palmicola are considered as new reports as fungal endophytes in oil palm.

Three endophytic ascomycetous fungi were able to secrete the highest EPS during submerged fermentation in our study namely Annulohypoxylon thailandicum P8 (Hypoxylaceae), Pseudopestalotiopsis simitheae P1 (Pestalotiopsidaceae), and Diaporthe eucalyptorum P11 (Diaporthaceae). Meanwhile, seven fungal endophytes did not produce any EPS after precipitation. This may suggest that the culture condition was not favorable for the carbohydrate secretion or EPS production by the strains. Microbial biosynthesis was mostly affected by growth condition, medium composition even different strain origins of the same genera/species as reported from previous studies (Maziero et al. 1999; Hao et al. 2010; Elisashvili 2012).

Different formulation using other C-sources such as maltose, starch, sorbitol, and sucrose for the fermentation medium may be investigated to optimize the growth of EPS-producing strains (Selbmann et al. 2002). The strain, A. thailandicum may be a new endophytic fungal genus/species in producing EPS compared to other EPSproducing strains observed in this study. Mahapatra and Banerjee (2016) already reported the EPS production by Pestalotiopsis sp. BC55 isolated from Andrographis paniculata with the highest yield $(4.32 \mathrm{~g} / \mathrm{L})$ detected during 3.76 days of incubation with glucose as C-source. Orlandelli et al. (2016) also reported several strains of Diaporthe spp. from Piper hispidum capable of producing EPS with different yields and conditions. A prominent strain namely Diaporthe sp. JF766998 was known to secrete the highest EPS $(15.4 \mathrm{mg} / 100 \mathrm{~mL})$ during 96 days of incubation. Hence, the quantity of EPS produced by $A$. thailandicum P8 (>50 mg/100 mL) was considerably higher than in previous reports.

FT-IR has been a useful tool for characterizing the structural and functional group of polysaccharides (Zhbankov 1997). FT-IR spectrum of EPS produced by $A$. thailandicum showed a strong peak and wide stretching at $3383.14 \mathrm{~cm}^{-1}$ which was oscillations of $-\mathrm{OH}$ groups present in hydrogen bond of polymer (Figure 4). The peak at $2924.09 \mathrm{~cm}^{-1}$ and $1381.03 \mathrm{~cm}^{-1}$ showed $\mathrm{C}-\mathrm{H}$ stretching and bending vibration, respectively. The peak at 1624.06 $\mathrm{cm}^{-1}$ was assigned as carbonyl bond $\mathrm{C}-\mathrm{O}$ of amide group in protein or peptide. The signal at $1072.42 \mathrm{~cm}^{-1}$ was obtained from glycosidic bonds $\mathrm{C}-\mathrm{O}-\mathrm{C}$ vibration. A typical absorption at $894.97 \mathrm{~cm}^{-1}$ suggested the presence of $\alpha$-anomeric in carbohydrate molecules (Zhbankov 1997; Prathyusha et al. 2018). Therefore, the FT-IR spectra of EPS by the occurrence of carboxyl, carbonyl, glycosidic bonds, and hydroxyl confirmed the characteristics of polysaccharides.

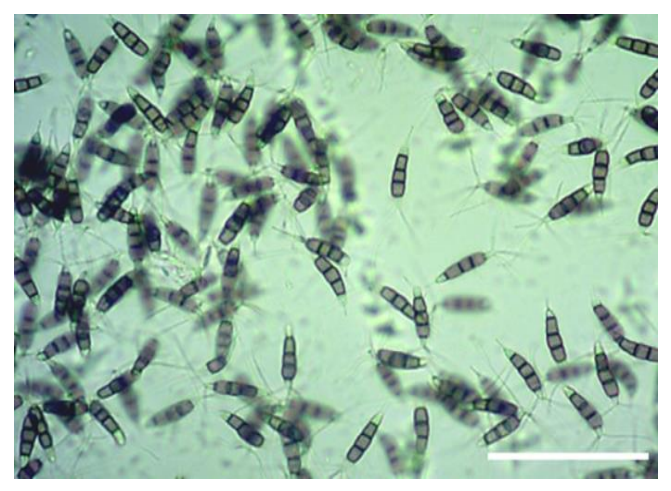

Figure 1. Microscopic view of typical conidium of endophytic Pestalotiopsis isolate. Scale bar: $50 \mu \mathrm{m}$ 
Table 1. BLAST hit results of endophytic fungi from oil palm, accession number and their EPS potential

\begin{tabular}{|c|c|c|c|c|}
\hline Isolate code & Nearest homolog sequences & Sequence identity \% & Accession numbers & EPS production ${ }^{\mathrm{a}}$ \\
\hline $\mathrm{P} 1$ & Pseudopestalotiopsis cocos & 99.28 & NR_145246 & +++ \\
\hline $\mathrm{P} 2-1$ & Poitrasia circinans & 90.88 & NR_145288 & - \\
\hline $\mathrm{P} 2-2$ & Curvularia petersonii & 96.83 & NR_158448 & + \\
\hline P2-3 & Pseudopestalotiopsis cocos & 99.28 & NR_145246 & + \\
\hline $\mathrm{P} 2-4$ & Pseudopithomyces palmicola & 100.00 & NR_154345 & ++ \\
\hline P2-6 & Lasiodiplodia theobromae & 100.00 & NR_111174 & + \\
\hline $\mathrm{P} 2-7$ & Aspergillus subflavus & 98.15 & NR_160622 & + \\
\hline $\mathrm{P} 2-8$ & Neopestalotiopsis eucalypticola & 100.00 & NR_163670 & + \\
\hline P2-9 & Neopestalotiopsis formicarum & 99.82 & NR_145242 & + \\
\hline $\mathrm{P} 2-10$ & Curvularia colcis & 97.62 & NR_147457 & - \\
\hline $\mathrm{P} 2-11$ & Thielaviopsis ethacetica & 100.00 & NR_155899 & - \\
\hline $\mathrm{P} 2-13$ & Neopestalotiopsis clavispora & 100.00 & NR_111782 & + \\
\hline $\mathrm{P} 2-14$ & Neopestalotiopsis clavispora & 100.00 & NR_111782 & ++ \\
\hline $\mathrm{P} 2-15$ & Pseudopestalotiopsis simitheae & 99.81 & NR_147541 & - \\
\hline $\mathrm{P} 2-16$ & Hypoxylon trugodes & 90.74 & NR_155160 & + \\
\hline P4 & Pestalotiopsis papuana & 100.00 & NR_147553 & + \\
\hline P5 & Hypoxylon haematostroma & 91.24 & NR_144918 & ++ \\
\hline P6 & Endomelanconiopsis endophytica & 99.83 & NR_156272 & + \\
\hline P8 & Annulohypoxylon thailandicum & 100.00 & NR_153529 & ++++ \\
\hline $\mathrm{P} 10$ & Curvularia soli & 98.16 & NR_152503 & ++ \\
\hline P11 & Diaporthe eucalyptorum & 95.67 & NR_120157 & +++ \\
\hline $\mathrm{P} 12$ & Hypoxylon liviae & 88.05 & NR_155154 & - \\
\hline $\mathrm{P} 13$ & Pestalotiopsis papuana & 100.00 & NR_147553 & + \\
\hline P14 & Daldinia starbaeckii & 98.81 & NR_147519 & - \\
\hline P15 & Flavodon ambrosius & 94.55 & NR_154000 & - \\
\hline P16 & Curvularia coatesiae & 100.00 & NR_158444 & + \\
\hline P17 & Beltraniella acacieae & 95.58 & NR_147685 & + \\
\hline P18 & Pseudopithomyces angolensis & 95.02 & NR_161121 & + \\
\hline P19 & Paracamarosporium fagi & 90.05 & NR_154318 & - \\
\hline
\end{tabular}

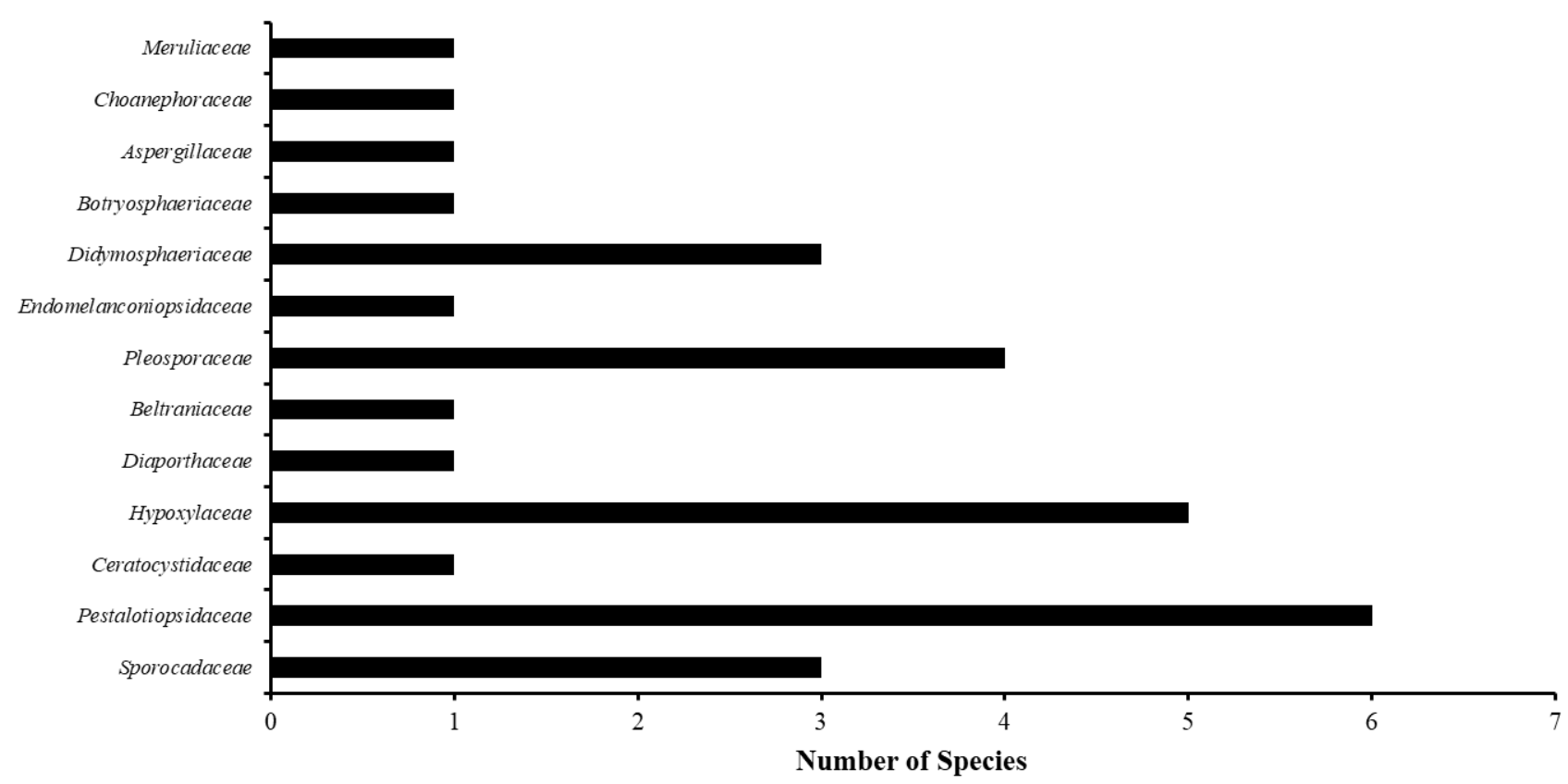

Figure 2. Number of endophytic fungal species per family isolated from the petioles of oil palm 


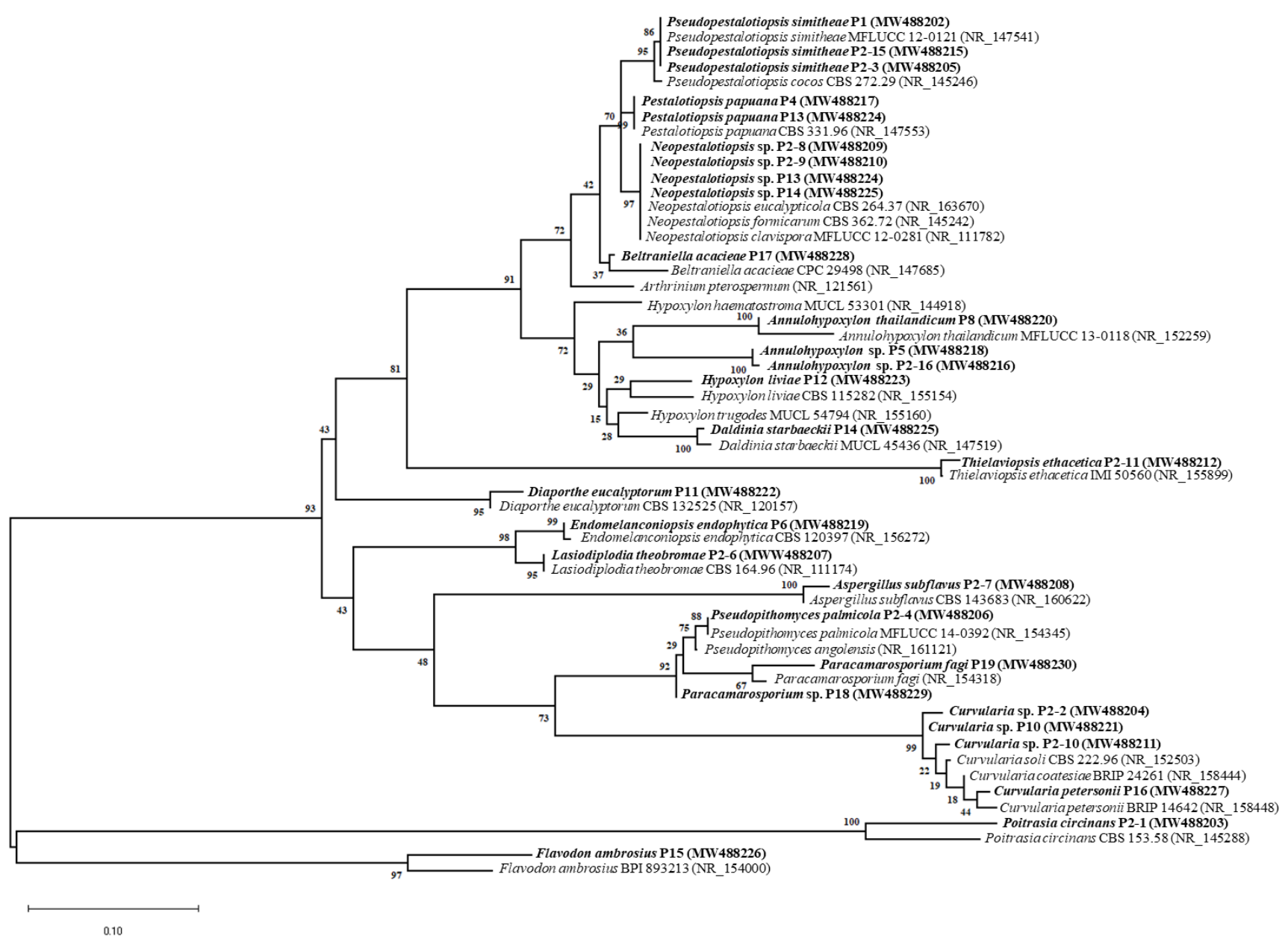

Figure 3. Phylogenetic analysis of endophytic fungi with closely related ITS-rDNA sequences retrieved from a GenBank database. Notes: Fungal species obtained in this study are shown in bold. Accession number of each individual is shown in brackets. Bootstrap values are indicated at the nodes of branches from $1000 \times$ replications.

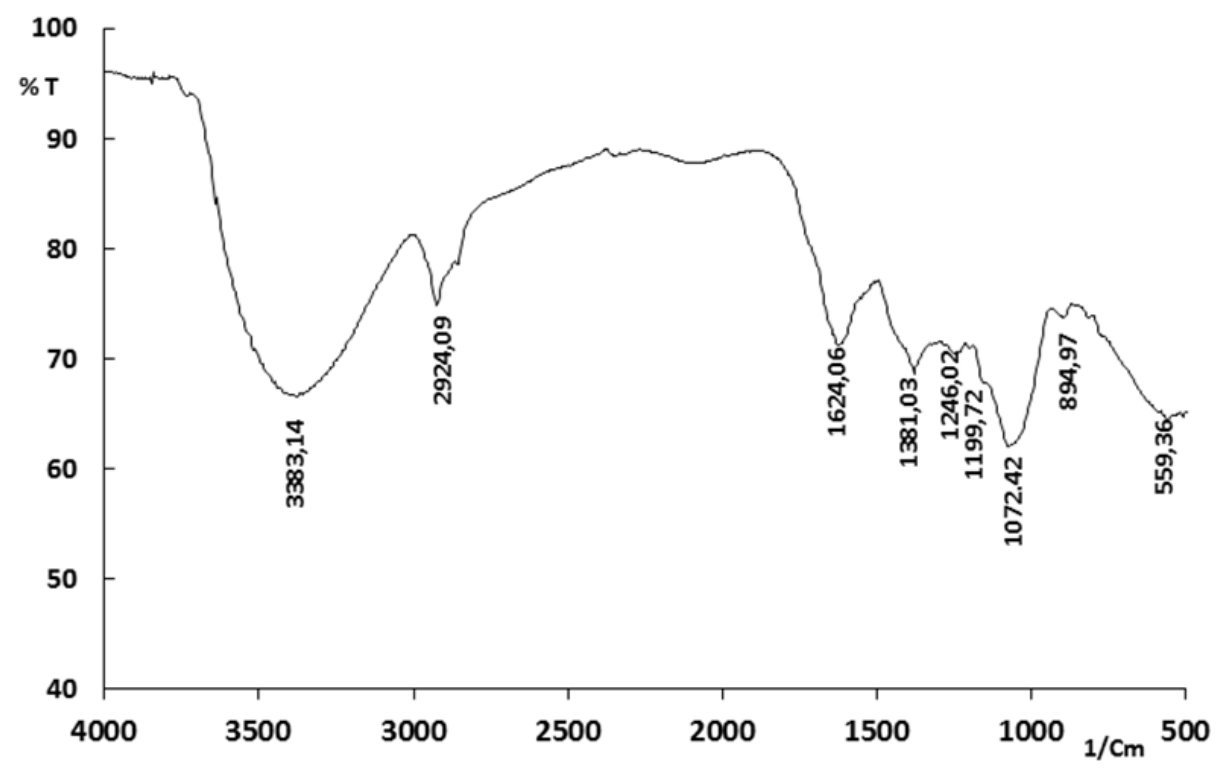

Figure 4. FT-IR spectrum of the EPS produced by A. thailandicum P8 


\section{ACKNOWLEDGEMENTS}

This study is fully funded and supported by Universitas Sumatera Utara through TALENTA funding scheme Research Grant No: 282/UN5.2.3.1/PPM/KP-TALENTA USU/2017, 22 Mei 2017.

\section{REFERENCES}

Aly AH, Debbab A, Kjer J, Proksch P. 2010. Fungal endophytes from higher plants: a prolific source of phytochemicals and other bioactive natural products. Fungal Divers 41: 1-16. DOI: 10.1007/s13225-0100034-4.

Ates O. 2015. Systems biology of microbial exopolysaccharides production. Front Bioeng Biotechnol 3: 200. DOI 10.3389/fbioe.2015.00200.

Chen Y, Mao W, Tao H, Zhu W, Qi X, Chen Y, Li H, Zhao C, Yang Y, Hou Y, Wang C, Li N. 2011. Structural characterization and antioxidant properties of an exopolysaccharide produced by the mangrove endophytic fungus Aspergillus sp. Y16. Bioresour Technol 102: 8179-8184. DOI: 10.1016/j.biortech.2011.06.048.

de Assis Costa OY, Tupinamba DD, Belgmann JC, Barreto CC, Quirino BF. 2018. Fungal diversity in oil palm leaves showing symptoms of fatal yellowing disease. PLoS ONE 13: e0191884. DOI 10.1371/journal.pone.0191884.

Dong QL, Lin TY, Xing XY, Chen B, Han Y. 2014. Identification of a symbiotic fungus from blue-green alga and its extracellular polysaccharide. Lett Appl Microbiol 58: 303-310. DOI: 10.1111/lam.12192.

Donot F, Fontana A, Baccou JC, Schorr-Galindo S. 2012. Microbia exopolysaccharides: Main examples of synthesis, excretion, genetics and extraction. Carbohydr Polym 87: 951-952.

Edgar RC. 2004. MUSCLE: Multiple Sequence Alignment with high accuracy and high throughput. Nucleic Acids Res. 32: 1792-1797. DOI: 10.1016/j.carbpol.2011.08.083

Elisashvili V. 2012. Submerged cultivation of medicinal mushrooms bioprocesses and products (review). Intl J Med Mushrooms 14: 211 239. DOI: 10.1615/IntJMedMushr.v14.i3.10.

Hao L, Xing X, Li Z, Zhang J, Sun J, Jia S, Qiao C, Wu T. 2010 Optimization of effect factors for mycelial growth and exopolysaccharide production by Schizophyllum commune. Appl Biochem Biotechnol 160: 621-631. DOI: 10.1007/s12010-008-85076.

Jeewon R, Liew ECY, Hyde KD. 2003. Molecular systematics of the Amphisphaeriaceae based on cladistic analyses of partial LSU rDNA gene sequences. Mycol Res 107: 1392-1402. DOI 10.1017/S095375620300875X.

Kavita K, Mishra A, Jha B. 2011. Isolation and physicochemical characterisation of extracellular polymeric substances by the marine bacterium Vibrio parahaemolyticus. Biofouling 27: 309-317. DOI 10.1080/08927014.2011.562605.

Koski LB, Golding GB. 2001. The closest BLAST hit is often not the nearest neighbor. $\mathrm{J}$ Mol Evol 52: 540-542. DOI: $10.1007 / \mathrm{s} 002390010184$

Kumar S, Stecher G, Li M, Knyaz C, Tamura K. 2018. MEGA X: Molecular evolutionary genetics analysis across computing platforms. Mol Biol Evol 35: 1547-1549. DOI: 10.1093/molbev/msy096.

Kusari S, Singh S, Jayabaskaran C. 2014. Biotechnological application of plant-associated endophytic fungi: Hope versus hype. Trends Biotechnol 32: 297-303. DOI: 10.1016/j.tibtech.2014.03.009.

Liu J, Wang X, Pu H, Liu S, Kan J, Jin C. 2016. Recent advances in endophytic exopolysaccharides: Production, structural characterization, physiological role and biological activity. Carbohydr Polym 157: 1113-1124. DOI: 10.1016/j.carbpol.2016.10.084.

Mahapatra S, Banerjee D. 2012. Structural elucidation and bioactivity of a novel exopolysaccharide from endophytic Fusarium solani SD5, Carbohydr Polym 90: 683-689. DOI: 10.1016/j.carbpol.2012.05.097.

Mahapatra S, Banerjee D. 2016. Production and structural elucidation of exopolysaccharide from endophytic Pestalotiopsis sp. BC55. Intl J Biol Macromol 82: 182-191. DOI: 10.1016/j.ijbiomac.2015.11.035.
Manganyi MC, Ateba CN. 2020. Untapped potentials of endophytic fungi: A review of novel bioactive compounds with biological applications. Microorganisms 8: 1934. DOI: 10.3390/microorganisms8121934.

Mata JA, Bejar V, Llamas I, Arias S, Bressolier P, Tallon R, Urdaci MC, Quesada E. 2006. Exopolysaccharides produced by the recently described halophilic bacteria Halomonas ventosae and Halomonas anticariensis. Res Microbiol 157: 827-835. DOI: 10.1016/j.resmic.2006.06.004

Maugeri TL, Gugliandolo C, Caccamo D, Panico A, Lama L, Gambacorta A, Nicolaus BA. 2002. Halophilic thermotolerant Bacillus isolated from a marine hot spring able to produce a new exopolysaccharide. Biotechnol Lett 24: 515-519. DOI: 10.1023/A:1014891431233.

Maziero R, Cavazzoni V, Bononi VLR. 1999. Screening of basidiomycetes for the production of exopolysaccharide and biomass in submerged culture. Rev Microbiol 30: 77-84. DOI: 10.1590/S000137141999000100015

Moscovici M. 2015. Present and future medical applications of microbial exopolysaccharides. Front Microbiol 6: 1012. DOI: 10.3389/fmicb.2015.01012.

Newman DJ, Cragg GM. 2015. Endophytic and epiphytic microbes as "sources" of bioactive agents. Front Chem 3: 1-13. DOI: 10.3389/fchem.2015.00034

Nisa H, Kamili AN, Nawchoo LA, Shafi S, Shameem N, Bandh SA. 2015. Fungal endophytes as prolific source of phytochemicals and other bioactive natural products: A review. Microb Pathog 82: 50-59. DOI: 10.1016/j.micpath.2015.04.001

Nwodo UU, Green E, Okoh A. 2012. Bacterial exopolysaccharides: Functionality and prospects. Intl J Mol Sci 13: 14002-14015. DOI: 10.3390/ijms131114002.

Orlandelli RC, Vasconcelos AF, Azevedo JL, da Silva MD, Pamphile JA. 2016. Screening of endophytic sources of exopolysaccharides: preliminary characterization of crude exopolysaccharide produced by submerged culture of Diaporthe sp. JF766998 under different cultivation time. Biochim Open 2: 33-40. DOI: 10.1016/j.biopen.2016.02.003.

Pinruan U, Rungjindamai N, Choeyklin R, Lumyong S, Hyde KD, Jones EBG. 2010. Occurrence and diversity of basidiomycetous endophytes from the oil palm, Elaeis guineensis in Thailand. Fungal Divers 41: 71-88. DOI: 10.1007/s13225-010-0029-1.

Prathyusha AMVN, Sheela GM, Bramhachari PV. 2018. Chemical characterization and antioxidant properties of exopolysaccharides from mangrove filamentous fungi Fusarium equiseti ANP2. Biotechnol Rep 19: e00277. DOI: 10.1016/j.btre.2018.e00277.

Ruffing A, Chen RR. 2006. Metabolic engineering of microbes for oligosaccharide and polysaccharide synthesis. Microb Cell Factories 5: 25. DOI: 10.1186/1475-2859-5-25.

Satpute SK, Banat IM, Dhakephalkar PK, Banpurkar AG, Chopade BA. 2010. Biosurfactants, emulsifiers and exopolysaccharides from marine microorganisms. Biotechnol Adv 28: 436-450. DOI: 10.1016/j.biotechadv.2010.02.006.

Selbmann L, Onofri S, Fenice M, Federici F, Petruccioli M. 2002. Production and structural characterization of the exopolysaccharide of the Antarctic fungus Phoma herbarum CCFEE 5080. Res Microbiol 153: 585-592. DOI: 10.1016/S0923-2508(02)01372-4.

Strobel G, Ford E, Worapong J, Harper JK, Arif AM, Grant DM, Fung PC, Chau MW. 2002. Isopestacin, an isobenzofuranone from Pestalotiopsis microspora, possessing antifungal and antioxidant activities. Phytochemistry 60: 179-183. DOI: 10.1016/S00319422(02)00062-6.

Suwannarach N, Sujarit K, Kumla J, Bussaban B, Lumyong S. 2013. First report of leaf spot disease on oil palm caused by Pestalotiopsis theae in Thailand. Dis Note 79: 277-279. DOI: 10.1007/s10327-013-04537.

Tamura K. 1992. Estimation of the number of nucleotide substitutions where they are strong transition-transversion $\mathrm{G}+\mathrm{C}$ content biases. Mol Biol Evol 9: 687-687.

Tan RX, Zou WX. 2001. Endophytes: A rich source of functional metabolites. Nat Prod Rep 18: 448-459. DOI: 10.1039/B100918O.

Torres-Mendoza D, Ortega HE, Cubilla-Rios L. 2020. Patents on endophytic fungi related to secondary metabolites and biotransformation applications. J Fungi 6: 58 . DOI: 10.3390/jof6020058. 
Watanabe K, Motohashi K, Ono Y. 2010. Description of Pestalotiopsis pallidotheae: a new species from Japan. Mycoscience 51 (3): 182 188. DOI: $10.1007 /$ S10267-009-0025-Z.

Yurnaliza, Aryantha INP, Esyanti RR, Susanto A. 2014. Antagonistic activity assessment of fungal endophytes from oil palm tissues against Ganoderma boninense Pat. Plant Pathol J 13: 257-267.

Yurnaliza, Esyanti RR, Susanto A, Aryantha INP. 2017. The chitinase activity of oil palm (Elaeis guineensis Jacq.) roots against fungal endophytes and pathogenic Ganoderma boninense. Plant OMICS 10: 247-251. DOI: 10.3316/informit.358845151497136.

Yurnaliza, Jamilah I. 2018. Isolation and identification of exopolysaccharide-producing endophytic fungi from leaf midribs of oil palm. J Phys Conf Ser 1116: 052080. DOI: 10.1088/1742 $6596 / 1116 / 5 / 052080$
Yurnaliza Y, Rambe DI, Sarimunggu L, Purba M, Nurwahyuni I, Lenny S, Lutfia A, Hartanto A. 2020. Screening of Burkholderia spp. from oil palm plantation with antagonistic properties against Ganoderma boninense. Biodiversitas 21: 3431-3437. DOI: 10.13057/biodiv/d210803.

Zhang H, Wang X, Li R, Sun X, Sun S, Li Q, Xu C. 2017. Preparation and bioactivity of exopolysaccharide from an endophytic fungus Chaetomium sp. of the medicinal plant Gynostemma pentaphylla. Pharmacogn Mag 13: 477-482. DOI: 10.4103/0973-1296.211033.

Zhbankov RG. 1997. Fourier transform IR and Raman spectroscopy structure of carbohydrates. J Mol Struct 436: 637-654. DOI: 10.1016/S0022-2860(97)00141-5 